\title{
Ligand-modulated ring expansion
}

\author{
Veronica Carta, ${ }^{a}$ and Mark J. MacLachlan*a \\ a Department of Chemistry, University of British Columbia, 2036 Main Mall, Vancouver, BC, V6T \\ 1Z1, Canada. \\ E-mail:vcarta@chem.ubc.ca
}

Tridentate planar bis(amido)pyridine ligands such as compound 1 have been widely exploited in supramolecular chemistry. Their ability to coordinate with square planar metals like palladium(II) and platinum(II), and the potential to modify their structures and bridge the phenyl moieties together make them suitable for forming catenanes, ${ }^{1,2}$ rotaxanes ${ }^{1,3}$ and molecular machines. ${ }^{4,5}$

We have prepared macrocycle 2 by bridging two hydroxyphenyl groups of $1(\mathrm{R}=\mathrm{OH})$ with 1,4-dichlorobutene. Coordination of $\mathrm{Pd}(\mathrm{II})$ to this macrocycle in acetonitrile produces compound 3. Ligand exchange between acetonitrile and six different ligands was investigated and a series of complexes was studied by detailed X-ray diffraction studies. In this poster, we present our study of the effect of macrocyclization on the exchange rates of various ligands to the palladium center (Figure 1). In addition, we explore how the presence of a bulky ligand coordinated to the palladium atom affects the metallomacrocycle reactivity toward ring opening metathesis polymerization.
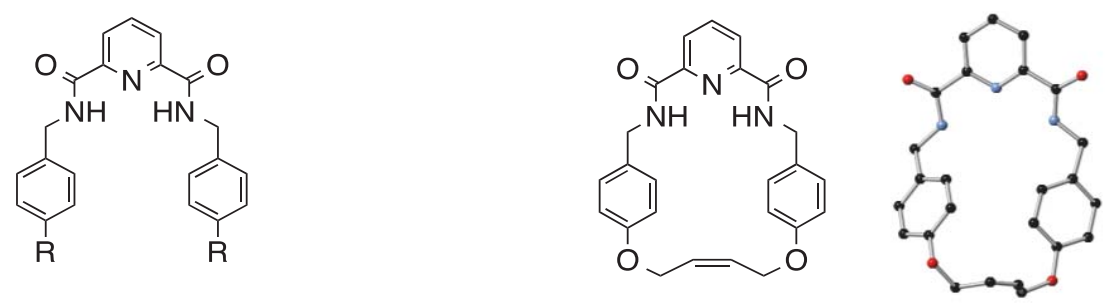

1

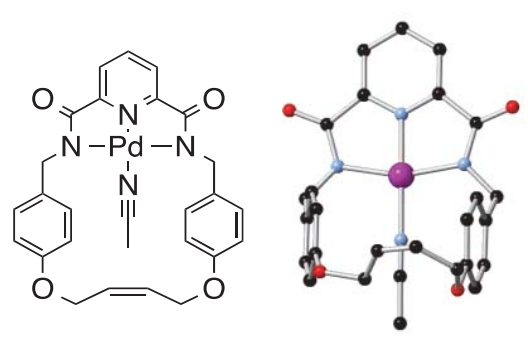

2

3

Figure 1. Chemical structure of compounds 1 and chemical and SCXRD structures of compounds 2 and 3

\section{References}

${ }^{1}$ Browne, C.; Ronson, T. K.; Nitschke, J. R. Angew. Chem. Int. Ed. 2014, 53, 10701.

${ }^{2}$ Fuller, A.-M. L.; Leigh, D. A.; Lusby, P. J.; Slawin, A. M. Z.; Walker, D. B. J. Am. Chem. Soc. 2005, 127, 12612.

${ }^{3}$ Ogawa, M.; Kawasaki, A.; Koyama, Y.; Takata, T. Polym. J. 2011, 43, 909.

${ }^{4}$ Beves, J. E.; Blanco, V.; Blight, B. A.; Carrillo, R.; D'Souza, D. M.; Howgego, D.; Leigh, D. A.; Slawin, A. M. Z.; Symes, M. D. J. Am. Chem. Soc. 2014, 136, 2094.

${ }^{5}$ Crowley, J. D.; Leigh, D. A.; Lusby, P. J.; McBurney, R. T.; Perret-Aebi, L.-E.; Petzold, C.; Slawin, A. M. Z.; Symes, M. D. J. Am. Chem. Soc. 2007, 129, 15085. 